\section{La Barrilería: El Museo Provincial de la Uva del Barco (Terque)}

El Museo Provincial de la Uva del Barco de Terque está dedicado a la conservación de los rasgos de identidad de la cultura parralera de la provincia de Almería.

Durante los siglos XIX y XX el cultivo y la comercialización en los mercados internacionales de la uva de mesa de Almería marcaron la vida económica y social de la provincia. El envase tradicional para la uva de Almería fue el barril. Algunas temporadas llegaron a salir del puerto de Almería cerca de dos millones y medio de barriles. Esta amplia demanda suponía una gran actividad artesanal, que se realizaba en los talleres de barrilería repartidos por toda la provincia incluida la capital. A satisfacer dicha demanda se dedicaron miles de hombres durante casi siglo y medio, pero su fin fue muy brusco en la década de sesenta y principios de los setenta, cuando el barril fue desbancado por la caja conocida como "plató" -pronunciación de la palabra francesa plateaux-, envase mucho más barato.

Esta actividad, desaparecida hace casi cuarenta años, se encuentra hoy en grave riesgo de extinción, pues los conocimientos de este difícil arte podrían perderse porque sólo los poseen un pequeño grupo de personas mayores.

Tal situación llevó al Museo a programar una serie de actividades y medidas para su recuperación y puesta en valor. En primer lugar, se realizó una investigación etnográfica centrada en la construcción de los barriles. Las entrevistas realizadas a los barrileros se complementaron con la localización de sus herramientas y de los documentos escritos y fotográficos que generó la actividad. Este trabajo se plasmó en el libro La Barrilería en Almería (2005), y en la exposición de los materiales en el propio Museo.

Otra iniciativa consistió en la recuperación de los propios barrileros. Para ello, en 2003, se organizó la I Jornada de recuperación de oficios antiguos, que se centró en una demostración de barrilería. La gran acogida que recibió por parte de los artesanos, y el gran atractivo turístico que representó llevó, en primer lugar, a la consolidación de estas jornadas, así como al desarrollo de un programa específico para su puesta en valor y difusión, el programa El Tiempo de la Uva del Barco. Coordinado por el Museo y la Diputación Provincial de Almería, lleva funcionando tres años, y, a través de él, se han realizado demostraciones de barrilería, exposiciones itinerantes (Las marcas comerciales de la uva de mesa de Almería, Las variedades históricas de la uva de Almería, etc.) y conferencias por todos los pueblos parraleros.

El éxito de estas demostraciones las ha llevado a formar parte de las actividades que ofrece el Museo a sus visitantes. Una vez al mes se realiza una demostración en visitas organizadas para grandes grupos de 200 personas (niños y adultos).

Como proyecto de futuro está la creación de un Taller de Barrilería en el que puedan trasmitirse las distintas técnicas y conocimientos a nuevos artesanos que encuentren en este envase una proyección comercial que asegure su conservación.

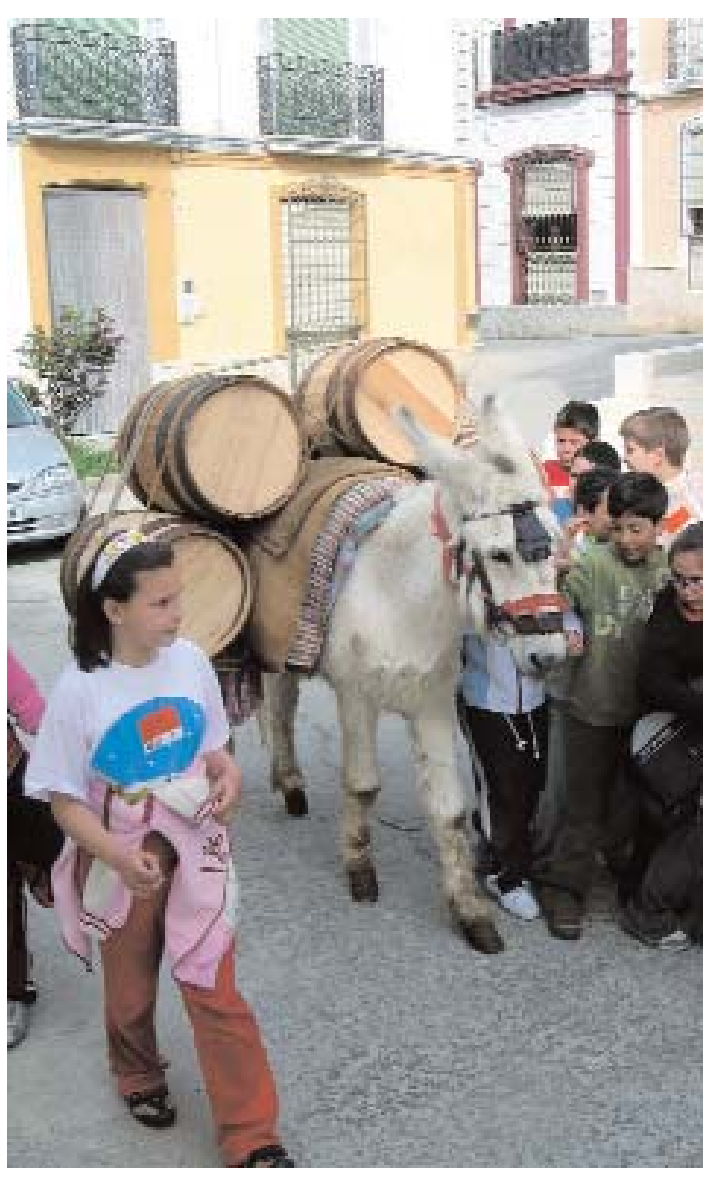

(1) Clase práctica de arriería de barriles con Pajarito / Fuente: Museo Provincial de LA UVA del Barco 


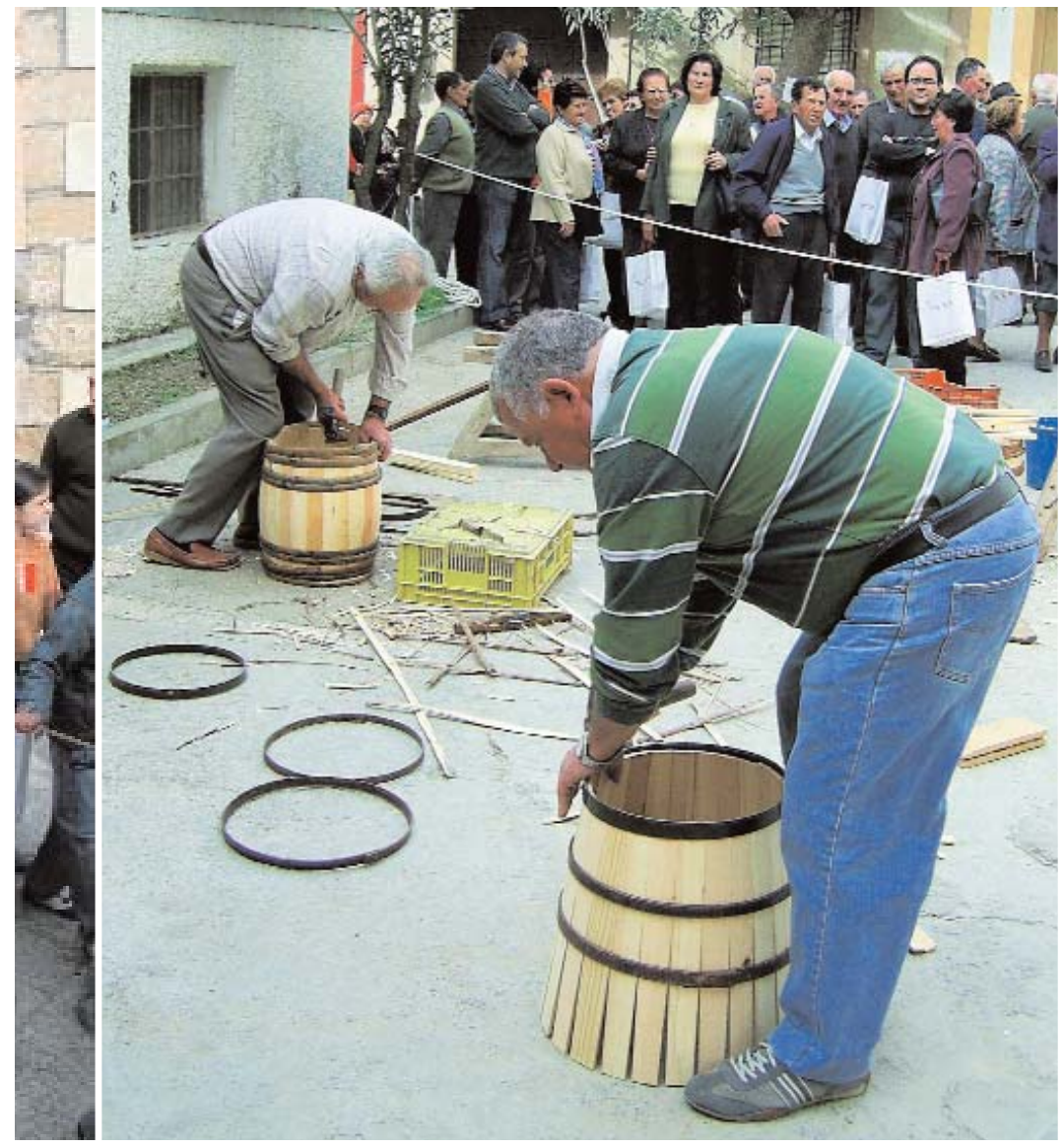

(1) Demostración de Barrilería / Fuente: Museo Provincial de LA UVA del Barco

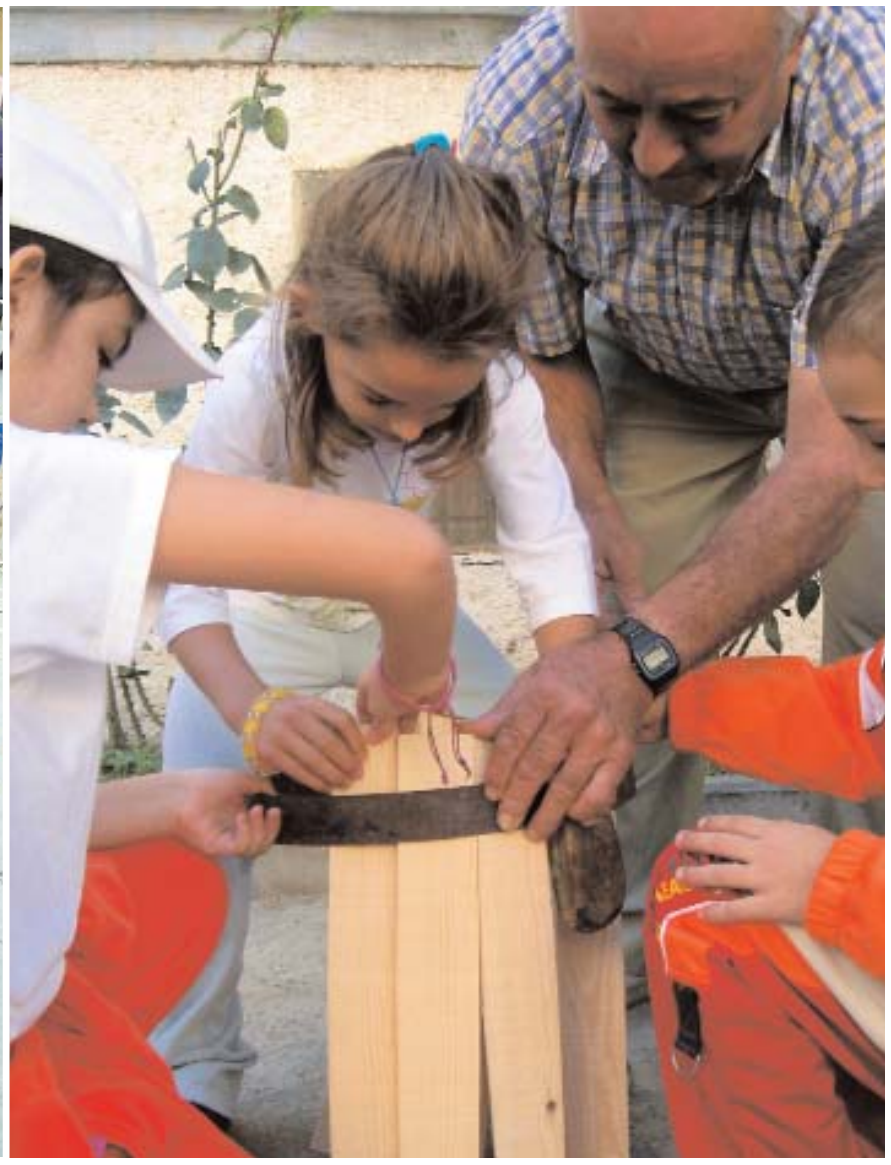

(1) Guillermo García con un grupo de niños / Fuente: Museo Provincial de LA UVA deL barco 